\title{
PET Molecular Imaging Research of Levodopa-Induced Dyskinesias in Parkinson's Disease
}

\author{
Gennaro Pagano $^{1} \cdot$ Tayyabah Yousaf $^{1} \cdot$ Marios Politis $^{1}$
}

Published online: 3 October 2017

(C) The Author(s) 2017. This article is an open access publication

\begin{abstract}
Purpose of Review To review the current status of positron emission tomography (PET) molecular imaging research of levodopa-induced dyskinesias (LIDs) in Parkinson's disease (PD).

Recent Findings Recent PET studies have provided robust evidence that LIDs in PD are associated with elevated and fluctuating striatal dopamine synaptic levels, which is a consequence of the imbalance between dopaminergic and serotonergic terminals, with the latter playing a key role in mishandling presynaptic dopamine release. Long-term exposure to levodopa is no longer believed to solely induce LIDs, as studies have highlighted that PD patients who go on to develop LIDs exhibit elevated putaminal dopamine release before the initiation of levodopa treatment, suggesting the involvement of other mechanisms, including altered neuronal firing and abnormal levels of phosphodiesterase 10A.

Summary Dopaminergic, serotonergic, glutamatergic, adenosinergic and opioid systems and phosphodiesterase $10 \mathrm{~A}$ levels have been shown to be implicated in the development of LIDs in PD. However, no system may be considered sufficient on its own for the development of LIDs, and the mechanisms underlying LIDs in PD may have a multisystem origin. In line with this notion, future studies should use multimodal PET molecular imaging in the same individuals to
\end{abstract}

This article is part of the Topical Collection on Neuroimaging

Marios Politis

marios.politis@kcl.ac.uk

1 Neurodegeneration Imaging Group, Maurice Wohl Clinical Neuroscience Institute, Institute of Psychiatry, Psychology \& Neuroscience, King's College London, 125 Coldharbour Lane, London, Camberwell SE5 9NU, UK shed further light on the different mechanisms underlying the development of LIDs in PD.

Keywords Dyskinesias $\cdot$ Parkinson's disease $\cdot$ Molecular imaging $\cdot$ Positron emission tomography

\section{Introduction}

More than 50 years since its discovery [1, 2], levodopa remains the gold standard in the management of motor symptoms of Parkinson's disease (PD) [3]. Although several systems are affected in PD, including dopaminergic, serotonergic, noradrenergic, cholinergic, glutamatergic, opioid and endocannabinoid systems [4], it is the loss of dopamine within the nigrostriatal pathway that leads to the emergence of the cardinal motor symptoms of PD [5]. Exogenous levodopa therapy fundamentally restores synaptic dopamine levels in the striatum, which is essential for the correct execution of movements [6]. However, despite its efficacy, long-term levodopa use is complicated by alterations in motor response, such as the development of levodopa-induced dyskinesias (LIDs) [7]. About $30 \%$ of PD patients develop LIDs after only 3 years of levodopa use [8], and approximately $80 \%$ of PD patients will develop LIDs over the course of the disease [9, 10].

The mechanisms underlying LIDs are still unclear. Levodopa induces sharp increases in striatal dopamine levels, which are particularly elevated in PD patients who experience LIDs [11]. However, the notion that LIDs are only due to high exposure to levodopa, which progressively lowers the threshold for dyskinesias until the administered concentration of levodopa needed for its antiparkinsonian action will produce LIDs, making the responses inseparable and causing pronounced motor fluctuations between an 'on' condition with dyskinesia and an 'off' condition with severe parkinsonism [12], has been questioned 
recently [13]. In PD patients who experience LIDs, the administration of a high dose of levodopa induces an antiparkinsonian response and dyskinesias at a comparable threshold. This observation indicates that the therapeutic window between the antiparkinsonian response and dyskinesia does not exist, except for the period before the emergence of dyskinesia, and that also other pathways are needed for the development of LIDs [13]. Another recent study has corroborated this hypothesis [14•]. Elevated putaminal dopamine release was present in de novo PD patients and was associated with an increased risk of later development of LIDs. This suggests that early compensatory changes in striatal dopamine turnover could be a diseaseintrinsic predisposing factor for the development of LIDs, maybe due to changes in non-dopaminergic pathways and not related to the long-term exposure to levodopa [14•]. A large number of studies have demonstrated that LIDs rely on a sequence of events, including abnormalities in corticostriatal neurotransmission, postsynaptic changes in proteins and gene expression, altered neuronal firing and plasticity $[15,16]$.

Molecular imaging modalities are able to identify minimal alterations at the nanomolecular level, and this is a prerequisite to understand subtle changes in brain activity [17, 18]. Positron emission tomography (PET) molecular probes bind a target, such as a receptor, a transporter or an enzyme, with high specificity and power of resolution [17]. PET molecular imaging has revolutionized the possibilities to gain insight into human brain biology and beyond this to understand the physiology and the pathophysiology of neurological diseases [17, 18]. PET radiotracers have provided invaluable insight into the mechanisms underlying LIDs, and have been used to measure dopaminergic [19], serotonergic [20], noradrenergic [21], cholinergic [22], glutamatergic [23], adenosinergic [24], opioid [25] and cannabinoid systems [24], phosphodiesterases [26] and other targets [27].

This review describes the current status of PET molecular imaging of LIDs, and its relation with the underlying mechanisms of PD.

\section{Presynaptic and Postsynaptic Mechanisms of LIDs}

Multiple components of the network between basal nuclei and cortex have been recognized as a substrate for the development of LIDs. At the molecular level, changes in signal transduction and neurotransmission occurring in specific populations of neurons have been linked to the emergence of LIDs [16].

The main component needed for the development of LIDs is a moderate-to-severe loss of dopaminergic terminals in the dorsal putamen, associated with the incapacity of the terminals to store dopamine. In this condition, the same amount of levodopa administered induces higher release of dopamine in the extracellular space [28]. At the same time, in the absence of enough intact dopaminergic terminals, exogenous levodopa is metabolized in other terminals expressing the enzyme aromatic L-amino acid decarboxylase (AADC), such as serotonergic and noradrenergic terminals, which do not possess the molecular machinery to properly control the release of dopamine. This results in higher swings in synaptic levels of dopamine and pulsatile stimulation of postsynaptic receptors located on striatal projection neurons [29].

Impaired presynaptic control of dopamine release from dopaminergic and non-dopaminergic terminals leads to overactivation of striatal dopaminergic receptors. This is a second component also needed for the development of LIDs. Abnormal activation of dopaminergic receptor $\mathrm{D}_{1}$ results in hyperactivation of the cyclic adenosine monophosphate (cAMP) signalling pathway [30]. $\mathrm{D}_{1}$ receptor-mediated activation of cAMP-dependent protein kinase A (PKA) and of dopamineand cAMP-regulated protein of $32 \mathrm{kDa}$ (DARPP-32) promotes the stimulation of additional intracellular signalling cascades involved in the regulation of gene transcription and protein synthesis [15]. Overactivation of dopaminergic receptor $\mathrm{D}_{3}$ has also been suggested in the development of LIDs [31].

Increased extracellular glutamate concentration [28] and changes in the subcellular distribution of glutamate [32] and adenosine [33] receptor subunits have also been associated with LIDs, together with alterations in the expression of messenger RNA that encodes the precursors of striatal neuropeptides preproenkephalin and preprodynorphin [34].

Within the striatum, cAMP signalling is finely regulated by phosphodiesterase 10A (PDE10A). Lesions in nigrostriatal dopaminergic projections in animal models of PD lead to an increase in cAMP levels [35], and treatment with levodopa reduces the high cAMP levels observed in the denervated striatum [35]. The cAMP levels in the corticostriatopallidal pathway are lower at the peak of LIDs compared with those in non-dyskinetic animals, and pretreatment with zaprinast, a non-selective PDE10A inhibitor, prevents the reduction of cAMP levels and reduces the severity of dyskinesias [36]. Altered striatal second-messenger signalling during dyskinesias may be due to the lost ability of striatal neurons to induce both depotentiation and long-term depression [37]. Hence, stimulation of postsynaptic striatal neurons by levodopaderived dopamine would fail, and dysregulation of PDE10A could be a pathogenic mechanism underlying the dysfunction of second-messenger signalling. We recently demonstrated that PDE10A levels are reduced in the striatum and globus pallidus of PD patients, and are associated with the severity of LIDs [26]. PDE10A might be the final regulator of striatal output, and modulation of its level may be crucial for the control of LIDs. We illustrate these mechanisms in Fig. 1.

\section{Molecular Imaging of the Dopaminergic System}

Dopamine release can be measured by PET with $\left[{ }^{11} \mathrm{C}\right]$ raclopride, a $\mathrm{D}_{2}$ receptor antagonist radioligand which competes with 
endogenous dopamine for $\mathrm{D}_{2}$ receptor binding. Changes in $\mathrm{D}_{2}$ receptor availability, as reflected by a reduction of baseline $\left[{ }^{11} \mathrm{C}\right]$ raclopride levels after levodopa administration, allows indirect measurement of synaptic dopamine release. PD patients with LIDs showed increased dopamine release after the administration of levodopa compared with PD patients with stable response to levodopa $[11,38]$. Greater reduction in putaminal $\left[{ }^{11} \mathrm{C}\right]$ raclopride levels has also been correlated with worse LIDs [39, 40••]. Also, PD patients with LIDs showed lower dopamine levels at $4 \mathrm{~h}$ from levodopa challenge, whereas PD patients with stable response to levodopa had unchanged putaminal dopamine levels [38]. This indicates that LIDs are associated with increased and fluctuating synaptic dopamine levels following levodopa administration [11, 38].

PET ligands for the presynaptic dopaminergic system such as $\left[{ }^{18} \mathrm{~F}\right]$ fluorodopa $\left(\left[{ }^{18} \mathrm{~F}\right] \mathrm{FDOPA}\right),\left[{ }^{18} \mathrm{~F}\right]$ dihydrotetrabenazine, and $\left[{ }^{18} \mathrm{~F}\right]$ fluoropropylcarbomethoxyiodophenylnortropane $\left(\left[{ }^{18} \mathrm{~F}\right] \mathrm{FP}-\mathrm{CIT}\right)$ or $\left[{ }^{11} \mathrm{C}\right]$ methylphenidate $\left(\left[{ }^{11} \mathrm{C}\right] \mathrm{MP}\right)$ are reliable tools to assess in vivo striatal AADC activity, the density of vesicular monoamine transporter 2 (VMAT2), and the availability of presynaptic dopamine transporters (DATs). The AADC catalyzes the decarboxylation of levodopa to dopamine, the VMAT2 is the vesicular transporter responsible for the transport of dopamine from the cytoplasm into secretory vesicles and a marker of dopamine storage in the dopaminergic terminals, and the DAT is responsible for the high-affinity uptake of dopamine from the synaptic cleft, respectively [41].

Putaminal AADC activity, measured by $\left[{ }^{18}\right.$ F]FDOPA PET, is lower in PD patients, and correlates with the severity of motor symptom rigidity and bradykinesia [42]. A retrospective study was recently performed in 31 de novo PD patients who underwent quantitative $\left[{ }^{18} \mathrm{~F}\right] \mathrm{FDOPA}$ PET to measure the effective distribution volume ratio, as a marker of dopamine release, and who were followed up to the development of LIDs [14•]. During a mean 7-year follow-up period, 35.5\% (11/31) developed LIDs. They had lower baseline effective distribution volume ratios in the putamen than those who did not develop LIDs, indicating higher dopamine release at the baseline, independently of the use of levodopa. PD patients with LIDs showed $12 \%$ reduction in caudate and $28 \%$ reduction in putaminal $\left[{ }^{18} \mathrm{~F}\right] \mathrm{FDOPA}$ uptake compared with PD patients with a stable response to levodopa [43]. At early stages of $\mathrm{PD}$, increased uptake of $\left[{ }^{18} \mathrm{~F}\right] \mathrm{FDOPA}$ in the serotonergic and noradrenergic terminals, which possibly reflects a compensatory upregulation of AADC, has also been shown, and in the globus pallidus internal segment, which possibly reflects dopamine storage capacity [44]. A recent study with $\left[{ }^{18} \mathrm{~F}\right]$ dihydrotetrabenazine showed that in advanced PD patients, lower VMAT2 density in the caudate, putamen and substantia nigra was correlated with the severity of motor complications [45]. The increase of $\left[{ }^{18} \mathrm{~F}\right]$ FDOPA uptake in the globus pallidus internal segment is lost with the progression of the disease in advanced PD patients with LIDs [44]. This may indicate that a loss of dopamine storage and capacity in the globus pallidus internal segment is also important for the development of LIDs. The role of the globus pallidus in the development of LIDs has also been confirmed at the postsynaptic level [46]. PD patients with LIDs showed higher $\mathrm{D}_{3}$ receptor levels in the globus pallidus, measured with $4-\left[{ }^{11} \mathrm{C}\right]$ propyl-9hydroxynaphthoxazine PET, compared with PD patients with stable response to levodopa [46]. This might reflect a $\mathrm{D}_{3}$ receptor upregulation in the globus pallidus and, together with the incapacity to store dopamine, the non-ability to sustain a normal pattern of pallidal output to motor cortex.

The presence of moderate-to-severe presynaptic dopaminergic terminal loss seems to play a role also in the development of LIDs, inducing an uncontrolled dopamine release [47]. A retrospective study conducted in 127 de novo patients with PD, who underwent $\left[{ }^{18} \mathrm{~F}\right] \mathrm{FP}$-CIT PET at the time of diagnosis, showed that lower putaminal DAT levels at baseline was a predictor of the development of LIDs at the 3-year follow-up. A study with $\left[{ }^{11} \mathrm{C}\right]$ MP PET showed that advanced PD patients with motor fluctuations and LIDs had reduced DAT expression in the putamen compared with advanced PD patients with motor fluctuations but no LIDs [48]. Integrity of DAT function is central in the regulation of dopamine levels in the synaptic cleft, and a gradual loss of DAT availability as PD progresses results in the loss of compensatory reuptake needed when dopamine levels substantially rise after a dose of levodopa [48].

LIDs are unlikely to result from alterations in striatal $\mathrm{D}_{1}$ or $\mathrm{D}_{2}$ receptor availability. PD patients with LIDs and PD patients without LIDs showed no differences in striatal $\mathrm{D}_{1}$ and $\mathrm{D}_{2}$ receptor availability, as assessed with $\left[{ }^{11} \mathrm{C}\right] \mathrm{SCH} 23390$ PET and $\left[{ }^{11} \mathrm{C}\right]$ raclopride PET, respectively [49].

This evidence is in support of the concept that an increased and fluctuating dopamine release is necessary but not sufficient for the development of LIDs, and other nondopaminergic pathways may play a role.

\section{Molecular Imaging of the Serotonergic System}

Serotonergic terminals express AADC, and are able to transform exogenous levodopa into dopamine [50]. PET ligands for presynaptic serotonergic transporter (SERT) such as $N, N-\left[{ }^{11} \mathrm{C}\right]$ dimethyl-2-(2-amino-4-cyanophenylthio)benzylamine $\left(\left[{ }^{11} \mathrm{C}\right] \mathrm{DASB}\right)$ are reliable tools to assess in vivo serotonergic terminals [51]. The serotonergic system is profoundly affected in PD, and its role in the development of LIDs has been evaluated in a recent meta-analysis [52•] and in several PET studies [40••, 53-55]. PD patients with LIDs showed a relative preservation of serotonergic terminals in the putamen, but the administration of the same levodopa dose induced markedly higher striatal synaptic dopamine release, evaluated with $\left[{ }^{11} \mathrm{C}\right]$ raclopride challenge, compared with PD patients with stable responses to levodopa. Oral administration of the serotonin receptor type 1A agonist 
A

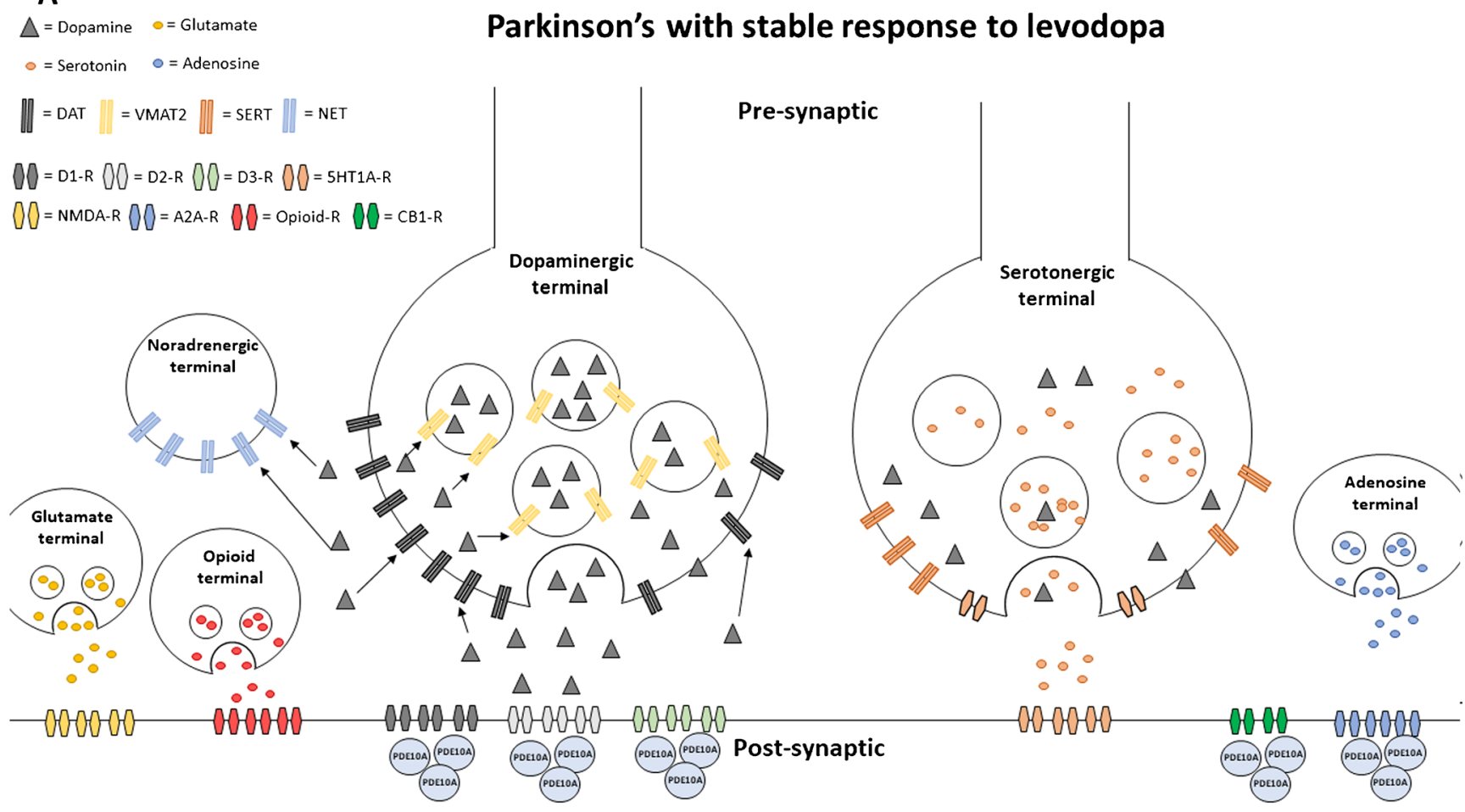

B

$\triangle=$ Dopamine $\odot=$ Glutamate

Parkinson's with LID

$0=$ Serotonin $0=$ Adenosine

$\|=$ DAT $\|=$ VMAT2 $\|=$ SERT $\|=$ NET

$D O=D 1-R D O=D 2-R D O=D 3-R \quad D O=5 H T 1 A-R$

$O D=$ NMDA-R $D D=$ A2A-R $D O=$ Opioid-R $D O=$ CB1-R

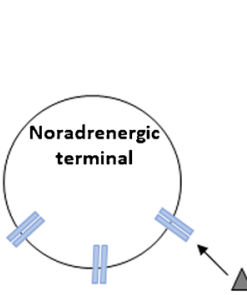

Glutamate
terminal

(2) 8

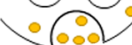

$\circ$
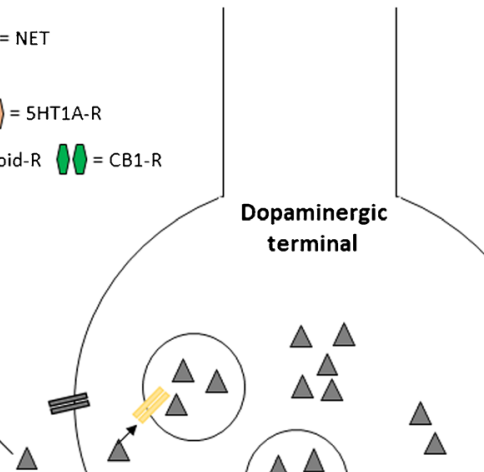

$\Delta \Delta$

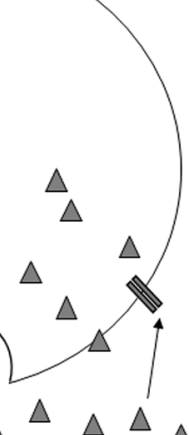

Pre-synaptic
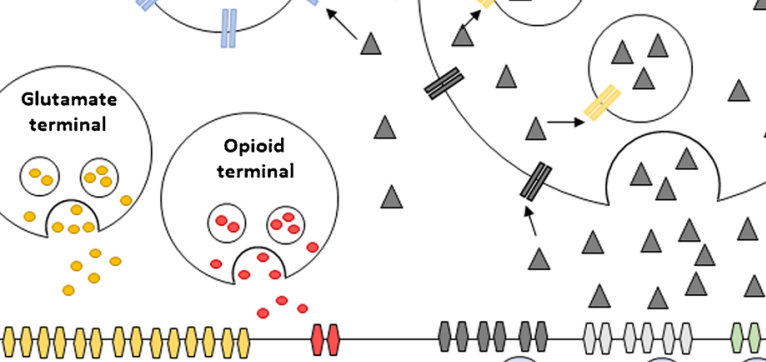

$\triangle \Delta$

$\Delta \Delta$

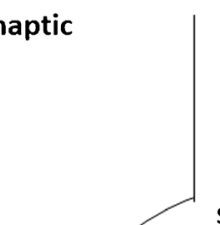

Seroton
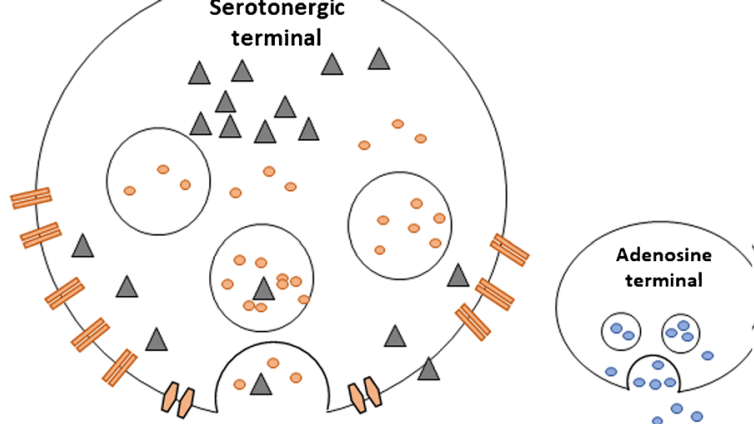

$\because \circ$

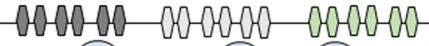

(20100) (00100) (00100)

Post-synaptic

OHOHOSO

HHO OHOHOHOO-

buspirone, a presynaptic modulator of the serotonergic system, before levodopa administration reduced levodopa-evoked striatal synaptic dopamine release and attenuated LIDs [40••]. Another study showed that PD patients with LIDs had no difference in striatal dopaminergic disease, assessed by $\left[{ }^{18} \mathrm{~F}\right] \mathrm{FP}-\mathrm{CIT}$ PET, compared with non-dyskinetic PD patients; however, the $\left[{ }^{11} \mathrm{C}\right] \mathrm{DASB}$ to $\left[{ }^{18} \mathrm{~F}\right] \mathrm{FP}-\mathrm{CIT}$ binding ratio (indicating serotoninergic to dopaminergic terminal availability) was higher in the putamen of PD patients with LIDs [53]. These findings were confirmed by another study, which demonstrated that the SERT to DAT ratio increases as PD progresses and patients experience LIDs [54]. Overall, these findings suggest that as the dopaminergic innervation in the striatum becomes critically low, the serotonergic system plays an important role in development 
4 Fig. 1 The pathways involved in the development of levodopa-induced dyskinesia (LID). a In Parkinson's disease patients with stable response to levodopa, dopamine transporter (DAT) takes up dopamine and it is stored in the presynaptic vesicles, via vesicular monoamine transporter 2 (VMAT2). As a consequence, dopamine levels remain relatively stable in the synaptic cleft, even after levodopa supplementation. Dopamine levels are maintained within a normal range as serotonergic terminals do not release dopamine excessively after levodopa supplementation, and DAT and noradrenaline transporter (NET) continue to take it up. At the postsynaptic level, the concentrations of dopaminergic, glutamatergic, adenosinergic, opioid and cannabinoid type 1 receptors are within the normal range. However, there is a decline in the concentration of phosphodiesterase 10A (PDE10A), which is an intracellular modulator of these receptors. b Parkinson's disease patients with LIDs lack the capacity to store dopamine, as a result of reduced VMAT2 levels, and fail to take up dopamine, due to the loss of DAT. This is associated with increased dopamine levels in the synaptic cleft. Excessive and inappropriate release of dopamine from serotonergic terminals contributes to the sharp increase of dopamine concentration after levodopa supplementation. At the postsynaptic level, the concentrations of glutamatergic and adenosinergic receptors are increased and those of opioid receptors are reduced. The concentrations of $\mathrm{D}_{1}, \mathrm{D}_{2}$ and cannabinoid type 1 receptors are within the normal range. Compared with Parkinson's disease patients with stable response to levodopa, there is a further decline of PDE10A concentration, which also correlates with the severity of dyskinesias. A2A-R adenosine $A_{2 A}$ receptor, CB1-R cannabinoid receptor type 1, D1-R dopamine receptor $\mathrm{D}_{1}$, D2-R dopamine receptor $\mathrm{D}_{2}$, D3-R dopamine receptor $\mathrm{D}_{3}, 5 \mathrm{HT} 1 \mathrm{~A}-\mathrm{R}$ serotonin receptor 1A, NMDA-R $N$-methyl-D-aspartate receptor, opioid$\mathrm{R}$ opioid receptor, SERT serotonin transporter

of LIDs by handling dopamine synaptic levels in an unregulated manner. Moreover, the role of the globus pallidus in the development of LIDs has been demonstrated also with $\left[{ }^{11} \mathrm{C}\right] \mathrm{DASB}$ PET. PD patients with LIDs had relative preservation of serotonergic terminals in the globus pallidus and increased pallidal dopamine release, measured with levodopa challenge and PET [55]. Serotonergic mechanisms such as excessive striatal innervation and high serotonin to dopamine striatal terminal ratio have also been associated with the development of graft-induced dyskinesias in PD patients who underwent striatal transplantation with fetal ventral mesencephalic tissue [56-58]. These findings support the role of serotonergic terminals in the aberrant release of striatal dopamine and in promoting the development of dyskinesias in patients with PD.

\section{Molecular Imaging of the Noradrenergic System}

The main presynaptic component of noradrenergic pathways is from the locus coeruleus projecting to the forebrain, including the striatum [59]. As for the serotonergic terminals, the noradrenergic terminals express AADC and are able to convert levodopa into dopamine [60]. Increased release of dopamine via noradrenergic terminals may promote dysregulated striatal dopamine levels and, consequently, LIDs [61]. A recent randomized clinical trial showed that fipamezole, a selective $\alpha_{2}-$ adrenergic receptor antagonist, was able to reduce LIDs without exacerbating parkinsonism [62]. Unfortunately, PET ligands for noradrenaline transporter such as 2-( $\alpha-\left(2-\left[{ }^{11} \mathrm{C}\right]\right.$ methoxyphenoxy $)$ benzyl $)$ morpholine or $\left[{ }^{11} \mathrm{C}\right]$ methyl reboxetine are not reliable tools to assess in vivo noradrenaline transporter activity [63], showing very low signal in the striatum. The development of selective PET radioligands tagging the noradrenergic system is warranted to better understand its involvement in the development of LIDs.

\section{Molecular Imaging of the Cholinergic System}

The main presynaptic component of cholinergic pathways is from the pedunculopontine nucleus pars compacta, projecting to the forebrain as well as various subcortical structures such as the thalamus [64]. Post-mortem studies in humans have shown decreases in acetylcholinesterase activity in PD patients with and without dementia [65]. PET ligands for the presynaptic cholinergic system such as $N-\left[{ }^{11} \mathrm{C}\right]$ methyl-4piperidyl acetate $\left(\left[{ }^{11} \mathrm{C}\right] \mathrm{MP} 4 \mathrm{~A}\right)$ and $N-\left[{ }^{11} \mathrm{C}\right]$ methylpiperidinyl propionate $\left(\left[{ }^{11} \mathrm{C}\right] \mathrm{PMP}\right)$ are reliable tools to assess in vivo acetylcholinesterase activity [66]. PET studies using $\left[{ }^{11} \mathrm{C}\right] \mathrm{MP} 4 \mathrm{~A}$ and $\left[{ }^{11} \mathrm{C}\right] \mathrm{PMP}$ have demonstrated $11-12 \%$ decreases in cortical and subcortical acetylcholinesterase activity in PD patients without dementia [67, 68]. No PET studies investigating the role of acetylcholinesterase in the development of LIDs have been performed in PD patients; thus, this component needs further investigation.

The main postsynaptic component of cholinergic pathways is from cholinergic neurons intrinsic to the striatum [69]. Global striatal output is significantly influenced by the cholinergic interneurons [70]. They represent less than 5\% of the total striatal neurons but provide a major contribution to the release of dopamine [71]. In preclinical studies, elevated cholinergic signalling has been associated with LIDs [72], and muscarinic and nicotinic receptor antagonists partially attenuated the expression of LIDs [73, 74]. LIDs may be attenuated by the ablation of the striatal cholinergic interneurons, without affecting the beneficial antiparkinsonian effect of levodopa [75]. Post-mortem studies in humans showed reduced levels of muscarinic and nicotinic receptors in the striatum of PD patients $[76,77]$. This potentially suggests a downregulation of the receptors induced by increased cholinergic signalling. PET ligands for the postsynaptic cholinergic system such as $\left[{ }^{18} \mathrm{~F}\right] \mathrm{A}-85380$ and $N-\left[{ }^{11} \mathrm{C}\right]$ methylpiperidyl benzilate $\left(\left[{ }^{11} \mathrm{C}\right] \mathrm{NMPB}\right)$ are reliable tools to assess in vivo nicotinic and muscarinic receptors respectively. A PET study using $\left[{ }^{18} \mathrm{~F}\right] \mathrm{A}-85380$ was performed in PD patients and showed reduced levels of nicotinic receptors in the striatum and substantia nigra compared with the levels in controls [78]. There were no associations between $\left[{ }^{18} \mathrm{~F}\right] \mathrm{A}-85380$ levels and disease severity, but LIDs have not been evaluated in detail. No PET studies have been performed in humans 
investigating the role of the cholinergic system in LIDs with $\left[{ }^{18} \mathrm{~F}\right] \mathrm{A}-85380,\left[{ }^{11} \mathrm{C}\right] \mathrm{NMPB}$ or other tracers; thus, this component needs further investigation.

\section{Molecular Imaging of the Glutamatergic System}

Glutamate is an excitatory neurotransmitter that acts through glutamate $N$-methyl-D-aspartate (NMDA) receptors, which include the NR1, NR2A and NR2B subtypes [79]. Experimental studies have shown that hyperphosphorylation of these subunits is associated with increased glutamatergic neurotransmission and the development of LIDs [80]. PET ligands for NMDA receptors such as $\left[{ }^{11} \mathrm{C}\right] \mathrm{CNS} 51619$ are reliable tools to investigate in vivo the glutamatergic system [81]. Only one PET study investigating the glutamatergic system has been performed in PD patients with LIDs [81]. PD patients not receiving medication had no differences in the basal nuclei and in the motor cortex compared with PD patients with stable response to levodopa. However, PD patients with LIDs receiving medication showed higher $\left[{ }^{11} \mathrm{C}\right] \mathrm{CNS} 51619$ uptake in the caudate, putamen and precentral gyrus compared with PD patients without LIDs, suggesting that dyskinetic patients may have abnormal glutamatergic transmission in motor areas following levodopa administration [81]. These findings support the hypothesis that glutamate transmission is important in the development of LIDs, and provide the physiological basis of why amantadine, a non-competitive antagonist of the NMDA receptor, is currently the most effective treatment for LIDs [82].

\section{Molecular Imaging of the Adenosinergic System}

Adenosine is an endogenous ligand for four receptor subtypes: $A_{1}, A_{2 A}, A_{2 B}$ and $A_{3}$ [89]. The adenosine $A_{2 A}$ receptors are expressed in the striatum and interact with the dopamine $\mathrm{D}_{2}$ receptor function, via the cAMP pathway [83]. PET ligands for the adenosinergic system such as $\left[1-\right.$ methyl $\left.{ }^{11}{ }^{11} \mathrm{C}\right] 8$ dicyclopropylmethyl-1-methyl-3-propylxanthine and [7methyl- $\left.{ }^{11} \mathrm{C}\right]-(E)-8-(3,4,5$-trimethoxystyryl)-1,3,7trimethylxanthine or $\left[{ }^{11} \mathrm{C}\right] \mathrm{SCH} 442,416$ are reliable tools to measure in vivo $A_{1 \mathrm{~A}}$ and $\mathrm{A}_{2 \mathrm{~A}}$ receptors, respectively. Two PET studies investigating the adenosinergic system have been performed in PD patients with LIDs [84, 85]. They both showed increased striatal adenosine $A_{2 A}$ receptor availability in PD patients with LIDs [84, 85]. $\mathrm{A}_{2 \mathrm{~A}}$ receptor binding sites could serve as potential pharmacological targets for the management of LIDs. A recent randomized clinical trial in PD patients with LIDs showed that use of KW-6002, a selective adenosine $\mathrm{A}_{2 \mathrm{~A}}$ receptor antagonist, was effective in alleviating this motor complication [86].

\section{Molecular Imaging of the Opioid System}

Three opioid receptors subtypes $(\mu, \kappa$ and $\delta$ ) are involved in regulating dopamine functions [87]. $\left[{ }^{11} \mathrm{C}\right]$ diprenorphine, a nonselective opioid receptor PET ligand, is a reliable tool to assess in vivo the opioid system [25]. The main limitation of this tracer is that it binds all three opioid receptor subtypes with similar affinity. One PET study has been performed with $\left[{ }^{11} \mathrm{C}\right]$ diprenorphine in PD patients, and showed reduced striatal, thalamic and cingulate opioid receptor binding and increased prefrontal opioid receptor binding in PD patients with LIDs compared with PD patients with stable response to levodopa [88]. No correlations were found between $\left[{ }^{11} \mathrm{C}\right]$ diprenorphine levels and PD severity, disease duration, or duration of levodopa treatment [88]. Further PET studies using more selective opioid radioligands could provide better insight into the role of the opioid system in the pathophysiology of LIDs.

\section{Molecular Imaging of the Cannabinoid System}

The cannabinoid type 1 (CB1) receptor is a seven transmembrane G-protein-linked receptor located predominantly in the striatal medium spiny neurons [89]. CB1 receptors inhibit adenylate cyclase by interacting with $\mathrm{G}_{\mathrm{i} / \mathrm{o}}$ proteins in the direct pathway, and they counteract $\mathrm{D}_{2}$ inhibition of adenylate cyclase coupling with $\mathrm{G}_{\mathrm{s}}$ proteins in the indirect pathway, thus having a key role in the control of movement [90]. Alterations in the availability of the cannabinoid receptors have also been related to the development of LIDs [91]. PET ligands such as $\left[{ }^{18} \mathrm{~F}\right] \mathrm{MK}$ 9470 are a reliable tool to measure in vivo CB1 receptors [92]. One study has been performed in PD patients, using $\left[{ }^{18} \mathrm{~F}\right] \mathrm{MK}$ 9470, which demonstrated a significant decrease in CB1 receptor availability in the substantia nigra compared with healthy controls. No correlation was found between reductions in CB1 receptor levels and the severity of LIDs [92]. Further PET studies with highly selective $\mathrm{CB} 1$ receptor radioligands, such as $(3 R, 5 R)-5-\left(3-\left[{ }^{11} \mathrm{C}\right] \mathrm{m}\right.$ e th ox y phenyl $)-3-((R)-1-$ phenylethylamino)-1-(4-trifluoromethylphenyl)pyrrolidin-2one [93], are needed to clarify the role of the cannabinoid system in the development of LIDs.

\section{Molecular Imaging of PDE10A}

PDE10A is mainly expressed in striatal medium spiny neurons, where it regulates the cAMP/PKA/DARPP-32 signalling cascade, thus plays a key role in the regulation of the global striatal output and in promoting neuronal survival [94, 95]. PDE10A has received increased attention since the observation that its pharmacological inhibition in a PD animal model significantly reduced motor symptoms and LIDs [96]. The PET ligand $\left[{ }^{11} \mathrm{C}\right] \mathrm{IMA} 107$ has been used to quantify PDE10A expression in vivo in 
moderate-advanced PD patients [26]. PD patients showed lower PDE10A levels in the caudate, putamen and globus pallidus compared with healthy controls. Higher Unified Dyskinesia Rating Scale scores in PD patients with LIDs correlated with lower PDE10A levels in the caudate and putamen [26]. This provides evidence for the role of PDE10A within the caudate and putamen in the development of LIDs in PD. Currently, a clinical trial (NCT02687542) is evaluating the effect of PDE10A inhibitors on motor complications in advanced PD patients.

\section{Conclusions}

Studies have provided robust evidence that LIDs in PD are associated with elevated and fluctuating striatal dopamine synaptic levels arising from an imbalanced dopaminergic to serotonergic terminal ratio, with the latter playing a key role in mishandling presynaptic dopamine release. However, other non-dopaminergic systems and pathways such as the glutamatergic, adenosinergic and opioid systems and phosphodiesterase 10A may play important roles in the development of LIDs in patients with PD. The implementation of novel PET ligands is warranted to unveil unexplored mechanisms of underlying pathophysiology of LIDs, and applications of multimodal PET molecular imaging approaches combining different tracers may shed further light on the mechanisms underlying the development of LIDs in PD.

\section{Compliance with Ethical Standards}

Conflict of Interest The authors declare that they have no competing interests.

Funding This study was not funded.

Open Access This article is distributed under the terms of the Creative Commons Attribution 4.0 International License (http:// creativecommons.org/licenses/by/4.0/), which permits unrestricted use, distribution, and reproduction in any medium, provided you give appropriate credit to the original author(s) and the source, provide a link to the Creative Commons license, and indicate if changes were made.

\section{References}

Papers of particular interest, published recently, have been highlighted as:

- Of importance

•• Of major importance

1. Birkmayer W, Hornykiewicz O. The effect of 1-3,4dihydroxyphenylalanine (= DOPA) on akinesia in parkinsonism 1961. Wien Klin Wochenschr. 2001;113(22):851-4.

2. Cotzias GC, Van Woert MH, Schiffer LM. Aromatic amino acids and modification of parkinsonism. N Engl J Med. 1967;276(7): 374-9. https://doi.org/10.1056/NEJM196702162760703.
3. Tarakad A, Jankovic J. Diagnosis and management of Parkinson's disease. Semin Neurol. 2017;37(2):118-26. https://doi.org/10. 1055/s-0037-1601888.

4. Niccolini F, Loane C, Politis M. Dyskinesias in Parkinson's disease: views from positron emission tomography studies. Eur J Neurol. 2014;21(5):694-9, e39-43. https://doi.org/10.1111/ene.12362.

5. Rodriguez-Oroz MC, Jahanshahi M, Krack P, Litvan I, Macias $\mathrm{R}$, Bezard E, et al. Initial clinical manifestations of Parkinson's disease: features and pathophysiological mechanisms. Lancet Neurol. 2009;8(12):1128-39. https://doi.org/10.1016/S14744422(09)70293-5.

6. Haber SN. The place of dopamine in the cortico-basal ganglia circuit. Neuroscience. 2014;282:248-57. https://doi.org/10.1016/j. neuroscience.2014.10.008.

7. Hametner E, Seppi K, Poewe W. The clinical spectrum of levodopa-induced motor complications. J Neurol. 2010;257(Suppl 2):S268-75. https://doi.org/10.1007/s00415010-5719-9.

8. Fahn S, Oakes D, Shoulson I, Kieburtz K, Rudolph A, Lang A, et al. Levodopa and the progression of Parkinson's disease. N Engl J Med. 2004;351(24):2498-508. https://doi.org/10.1056/ NEJMoa033447.

9. Poewe WH, Lees AJ, Stern GM. Low-dose L-dopa therapy in Parkinson's disease: a 6-year follow-up study. Neurology. 1986;36(11):1528-30.

10. Ahlskog JE, Muenter MD. Frequency of levodopa-related dyskinesias and motor fluctuations as estimated from the cumulative literature. Mov Disord. 2001;16(3):448-58.

11. de la Fuente-Fernandez R, Sossi V, Huang Z, Furtado S, Lu JQ, Calne DB, et al. Levodopa-induced changes in synaptic dopamine levels increase with progression of Parkinson's disease: implications for dyskinesias. Brain. 2004;127(Pt 12):2747-54. https://doi.org/ 10.1093/brain/awh290.

12. Niccolini F, Rocchi L, Politis M. Molecular imaging of levodopainduced dyskinesias. Cell Mol Life Sci. 2015;72(11):2107-17. https://doi.org/10.1007/s00018-015-1854-x.

13. Nutt JG, Chung KA, Holford NH. Dyskinesia and the antiparkinsonian response always temporally coincide: a retrospective study. Neurology. 2010;74(15):1191-7. https://doi.org/10. 1212/WNL.0b013e3181d90050.

14. Lohle M, Mende J, Wolz M, Beuthien-Baumann B, Oehme L, van den Hoff $\mathrm{J}$, et al. Putaminal dopamine turnover in de novo Parkinson disease predicts later motor complications. Neurology. 2016;86(3):231-40. https://doi.org/10.1212/WNL. 0000000000002286 . Lohle et al. evaluated the power of prediction of the striatal $\left[{ }^{18} \mathrm{~F}\right]$ dopa effective distribution volume ratio (as the inverse of dopamine turnover) in 31 de novo PD patients before dopaminergic supplementation. PD patients who developed LIDs at follow-up had a higher effective distribution volume ratio at the baseline, indicating elevated putaminal dopamine turnover. These findings indicated that PD patients who go on to develop LIDs had a disease-intrinsic predisposing factor to exhibit elevated putaminal dopamine release before the initiation of levodopa treatment and suggested the involvement of other mechanisms, including altered neuronal firing and plasticity, in the development of LIDs.

15. Bastide MF, Meissner WG, Picconi B, Fasano S, Fernagut PO, Feyder M, et al. Pathophysiology of L-dopa-induced motor and non-motor complications in Parkinson's disease. Prog Neurobiol. 2015;132:96-168. https://doi.org/10.1016/j. pneurobio.2015.07.002.

16. Carta AR, Mulas G, Bortolanza M, Duarte T, Pillai E, Fisone G, et al. L-DOPA-induced dyskinesia and neuroinflammation: do microglia and astrocytes play a role? Eur J Neurosci. 2017;45(1):7391. https://doi.org/10.1111/ejn.13482. 
17. Pagano G, Niccolini F, Politis M. Current status of PET imaging in Huntington's disease. Eur J Nucl Med Mol Imaging. 2016;43(6): 1171-82. https://doi.org/10.1007/s00259-016-3324-6.

18. Politis M, Piccini P. Positron emission tomography imaging in neurological disorders. J Neurol. 2012;259(9):1769-80. https://doi.org/ 10.1007/s00415-012-6428-3.

19. Niccolini F, Su P, Politis M. Dopamine receptor mapping with PET imaging in Parkinson's disease. J Neurol. 2014;261(12):2251-63. https://doi.org/10.1007/s00415-014-7302-2.

20. Politis M, Niccolini F. Serotonin in Parkinson's disease. Behav Brain Res. 2015;277:136-45. https://doi.org/10.1016/j.bbr. 2014.07.037.

21. Adhikarla V, Zeng F, Votaw JR, Goodman MM, Nye JA. Compartmental modeling of $\left[{ }^{11} \mathrm{C}\right]$ MENET binding to the norepinephrine transporter in the healthy human brain. Nucl Med Biol. 2016;43(5):318-23. https://doi.org/10.1016/j.nucmedbio. 2016.02.008.

22. Roy R, Niccolini F, Pagano G, Politis M. Cholinergic imaging in dementia spectrum disorders. Eur J Nucl Med Mol Imaging. 2016;43(7):1376-86. https://doi.org/10.1007/s00259-016-3349-x.

23. Stone JM. Imaging the glutamate system in humans: relevance to drug discovery for schizophrenia. Curr Pharm Des. 2009; 15(22):2594-602.

24. Tronel C, Largeau B, Santiago Ribeiro MJ, Guilloteau D, Dupont AC, Arlicot N. Molecular targets for PET imaging of activated microglia: the current situation and future expectations. Int J Mol Sci. 2017;18(4). https://doi.org/10.3390/ijms18040802.

25. Sadzot B, Price JC, Mayberg HS, Douglass KH, Dannals RF, Lever $\mathrm{JR}$, et al. Quantification of human opiate receptor concentration and affinity using high and low specific activity $\left[{ }^{11} \mathrm{C}\right]$ diprenorphine and positron emission tomography. J Cereb Blood Flow Metab. 1991;11(2):204-19. https://doi.org/10.1038/jcbfm.1991.52.

26. Niccolini F, Foltynie T, Reis Marques T, Muhlert N, Tziortzi AC, Searle GE, et al. Loss of phosphodiesterase 10A expression is associated with progression and severity in Parkinson's disease. Brain. 2015;138(Pt 10):3003-15. https://doi.org/10.1093/brain/awv219.

27. Loane C, Politis M. Positron emission tomography neuroimaging in Parkinson's disease. Am J Transl Res. 2011;3(4):323-41.

28. Lindgren HS, Andersson DR, Lagerkvist S, Nissbrandt H, Cenci MA. L-DOPA-induced dopamine efflux in the striatum and the substantia nigra in a rat model of Parkinson's disease: temporal and quantitative relationship to the expression of dyskinesia. J Neurochem. 2010;112(6):1465-76. https://doi.org/10.1111/j.14714159.2009.06556.x.

29. Carta M, Bezard E. Contribution of pre-synaptic mechanisms to LDOPA-induced dyskinesia. Neuroscience. 2011;198:245-51. https://doi.org/10.1016/j.neuroscience.2011.07.070.

30. Santini E, Valjent E, Usiello A, Carta M, Borgkvist A, Girault JA, et al. Critical involvement of cAMP/DARPP-32 and extracellular signal-regulated protein kinase signaling in L-DOPA-induced dyskinesia. J Neurosci. 2007;27(26):6995-7005. https://doi.org/10. 1523/JNEUROSCI.0852-07.2007.

31. Visanji NP, Fox SH, Johnston T, Reyes G, Millan MJ, Brotchie JM. Dopamine $\mathrm{D}_{3}$ receptor stimulation underlies the development of LDOPA-induced dyskinesia in animal models of Parkinson's disease. Neurobiol Dis. 2009;35(2):184-92. https://doi.org/10.1016/j.nbd. 2008.11.010.

32. Silverdale MA, Kobylecki C, Hallett PJ, Li Q, Dunah AW, Ravenscroft P, et al. Synaptic recruitment of AMPA glutamate receptor subunits in levodopa-induced dyskinesia in the MPTPlesioned nonhuman primate. Synapse. 2010;64(2):177-80. https:// doi.org/10.1002/syn.20739.

33. Kanda T, Jackson MJ, Smith LA, Pearce RK, Nakamura J, Kase H, et al. Combined use of the adenosine $\mathrm{A}_{2 \mathrm{~A}}$ antagonist $\mathrm{KW}-6002$ with L-DOPA or with selective D1 or D2 dopamine agonists increases antiparkinsonian activity but not dyskinesia in MPTP-treated monkeys. Exp Neurol. 2000;162(2):321-7. https://doi.org/10. 1006/exnr.2000.7350.

34. Cenci MA, Lee CS, Bjorklund A. L-DOPA-induced dyskinesia in the rat is associated with striatal overexpression of prodynorphinand glutamic acid decarboxylase mRNA. Eur J Neurosci. 1998;10(8):2694-706.

35. Hossain MA, Weiner N. Dopaminergic functional supersensitivity: effects of chronic L-dopa and carbidopa treatment in an animal model of Parkinson's disease. J Pharmacol Exp Ther. 1993;267(3):110511.

36. Giorgi M, D'Angelo V, Esposito Z, Nuccetelli V, Sorge R, Martorana A, et al. Lowered cAMP and cGMP signalling in the brain during levodopa-induced dyskinesias in hemiparkinsonian rats: new aspects in the pathogenetic mechanisms. Eur J Neurosci. 2008;28(5):941-50. https://doi.org/10.1111/j.14609568.2008.06387.x.

37. Picconi B, Bagetta V, Ghiglieri V, Paille V, Di Filippo M, Pendolino $\mathrm{V}$, et al. Inhibition of phosphodiesterases rescues striatal long-term depression and reduces levodopa-induced dyskinesia. Brain. 2011;134(Pt 2):375-87. https://doi.org/10.1093/brain/awq342.

38. de la Fuente-Fernandez R, Lu JQ, Sossi V, Jivan S, Schulzer $\mathrm{M}$, Holden JE, et al. Biochemical variations in the synaptic level of dopamine precede motor fluctuations in Parkinson's disease: PET evidence of increased dopamine turnover. Ann Neurol. 2001;49(3):298-303.

39. Pavese N, Evans AH, Tai YF, Hotton G, Brooks DJ, Lees AJ, et al. Clinical correlates of levodopa-induced dopamine release in Parkinson disease: a PET study. Neurology. 2006;67(9):1612-7. https://doi.org/10.1212/01.wnl.0000242888.30755.5d.

40.• Politis M, Wu K, Loane C, Brooks DJ, Kiferle L, Turkheimer FE, et al. Serotonergic mechanisms responsible for levodopa-induced dyskinesias in Parkinson's disease patients. J Clin Invest. 2014;124(3):1340-9. https://doi.org/10.1172/JCI71640. Politis et al. investigated serotonergic mechanisms in LID development in PD patients using $\left[{ }^{11}\right.$ C]DASB PET to evaluate serotonin terminal function and ${ }^{11} \mathrm{C} \mid$ raclopride PET challenge to evaluate dopamine release. Identical levodopa doses induced markedly higher striatal synaptic dopamine concentrations in PD patients with LIDs compared with PD patients with stable responses to levodopa. PD patients with LIDs showed relative preservation of serotonergic terminals within the putamen. Oral administration of the serotonin receptor type $1 \mathrm{~A}$ agonist buspirone before levodopa reduced levodopa-evoked striatal synaptic dopamine increases and attenuated LIDs. PD patients with LIDs who exhibited greater decreases in synaptic dopamine concentrations after buspirone pretreatment had higher levels of serotonergic terminal functional integrity. These findings indicate that striatal serotonergic terminals contribute to LID pathophysiology via aberrant processing of exogenous levodopa and release of dopamine as a false neurotransmitter in the striatum of PD patients who experience LIDs.

41. Brooks DJ, Pavese N. Imaging biomarkers in Parkinson's disease. Prog Neurobiol. 2011;95(4):614-28. https://doi.org/10.1016/j. pneurobio.2011.08.009.

42. Otsuka M, Ichiya Y, Kuwabara Y, Hosokawa S, Sasaki M, Yoshida T, et al. Differences in the reduced 18F-Dopa uptakes of the caudate and the putamen in Parkinson's disease: correlations with the three main symptoms. J Neurol Sci. 1996;136(1-2):169-73.

43. de la Fuente-Fernández R, Pal PK, Vingerhoets FJ, Kishore A, Schulzer M, Mak EK, et al. Evidence for impaired presynaptic dopamine function in Parkinsonian patients with motor fluctuations. J Neural Transm (Vienna). 2000;107(1):49-57. https://doi. org/10.1007/s007020050004.

44. Whone AL, Moore RY, Piccini PP, Brooks DJ. Plasticity of the nigropallidal pathway in Parkinson's disease. Ann Neurol. 2003;53(2):206-13. https://doi.org/10.1002/ana.10427. 
45. Hsiao IT, Weng YH, Hsieh CJ, Lin WY, Wey SP, Kung MP, et al. Correlation of Parkinson disease severity and 18F-DTBZ positron emission tomography. JAMA Neurol. 2014;71(6):758-66. https:// doi.org/10.1001/jamaneurol.2014.290.

46. Payer DE, Guttman M, Kish SJ, Tong J, Adams JR, Rusjan P, et al. $\mathrm{D}_{3}$ dopamine receptor-preferring $\left[{ }^{11} \mathrm{C}\right] \mathrm{PHNO}$ PET imaging in Parkinson patients with dyskinesia. Neurology. 2016;86(3):22430. https://doi.org/10.1212/WNL.0000000000002285.

47. Hong JY, Oh JS, Lee I, Sunwoo MK, Ham JH, Lee JE, et al. Presynaptic dopamine depletion predicts levodopa-induced dyskinesia in de novo Parkinson disease. Neurology. 2014;82(18):1597604. https://doi.org/10.1212/WNL.0000000000000385.

48. Troiano AR, de la Fuente-Fernandez R, Sossi V, Schulzer M, Mak E, Ruth TJ, et al. PET demonstrates reduced dopamine transporter expression in PD with dyskinesias. Neurology. 2009;72(14):12116. https://doi.org/10.1212/01.wnl.0000338631.73211.56.

49. Turjanski N, Lees AJ, Brooks DJ. In vivo studies on striatal dopamine $\mathrm{D}_{1}$ and $\mathrm{D}_{2}$ site binding in L-dopa-treated Parkinson's disease patients with and without dyskinesias. Neurology. 1997;49(3):717-23.

50. Carta M, Carlsson T, Munoz A, Kirik D, Bjorklund A. Role of serotonin neurons in the induction of levodopa- and graft-induced dyskinesias in Parkinson's disease. Mov Disord. 2010;25 Suppl 1: S174-9. https://doi.org/10.1002/mds.22792.

51. Houle S, Ginovart N, Hussey D, Meyer JH, Wilson AA. Imaging the serotonin transporter with positron emission tomography: initial human studies with $\left[{ }^{11} \mathrm{C}\right]$ DAPP and $\left[{ }^{11} \mathrm{C}\right] \mathrm{DASB}$. Eur J Nucl Med. 2000;27(11):1719-22.

52. Pagano G, Niccolini F, Fusar-Poli P, Politis M. Serotonin transporter in Parkinson's disease: a meta-analysis of positron emission tomography studies. Ann Neurol. 2017;81(2):171-80. https://doi.org/ 10.1002/ana.24859.53. Pagano et al. systematically examined the evidence of SERT integrity in PD as measured by $\left[{ }^{11} \mathrm{C}\right]$ DASB PET, for articles published in the MEDLINE, Web of Science, Cochrane and Scopus databases up to 1 July 2016. Twenty PET studies investigating $\left[{ }^{11} \mathrm{C}\right] \mathrm{DASB}$ binding in PD patients $(n=234)$ and healthy controls $(n=225)$ were included in the meta-analysis. PD patients showed a significant reduction of $\left[{ }^{11} \mathrm{C}\right] \mathrm{DASB}$ binding in raphe nuclei, caudate, putamen, ventral striatum, thalamus and hypothalamus compared with healthy controls. Lower putaminal $\left[{ }^{11}\right.$ C $]$ DASB binding correlated with longer disease duration. PD patients with LIDs showed preserved putaminal $\left[{ }^{11}\right.$ C]DASB binding compared with non-dyskinetic PD patients. These findings indicate that SERT binding progressively decreases in PD patients, but in those who develop LIDs, there is an aberrant spreading of serotonergic terminals, which further confirms the striatal serotonergic contribution to LIDs.

53. Lee JY, Seo S, Lee JS, Kim HJ, Kim YK, Jeon BS. Putaminal serotonergic innervation: monitoring dyskinesia risk in Parkinson disease. Neurology. 2015;85(10):853-60. https://doi.org/10.1212/ WNL.0000000000001909.

54. Roussakis AA, Politis M, Towey D, Piccini P. Serotonin-todopamine transporter ratios in Parkinson disease: relevance for dyskinesias. Neurology. 2016;86(12):1152-8. https://doi.org/10. 1212/WNL.0000000000002494.

55. Smith R, Wu K, Hart T, Loane C, Brooks DJ, Bjorklund A, et al. The role of pallidal serotonergic function in Parkinson's disease dyskinesias: a positron emission tomography study. Neurobiol Aging. 2015;36(4):1736-42. https://doi.org/10.1016/j. neurobiolaging.2014.12.037.

56. Politis M, Wu K, Loane C, Quinn NP, Brooks DJ, Rehncrona S, et al. Serotonergic neurons mediate dyskinesia side effects in Parkinson's patients with neural transplants. Sci Transl Med. 2010;2(38):38ra46. https://doi.org/10.1126/scitranslmed.3000976.
57. Politis M. Dyskinesias after neural transplantation in Parkinson's disease: what do we know and what is next? BMC Med. 2010;8: 80. https://doi.org/10.1186/1741-7015-8-80.

58. Politis M, Oertel WH, Wu K, Quinn NP, Pogarell O, Brooks DJ, et al. Graft-induced dyskinesias in Parkinson's disease: High striatal serotonin/dopamine transporter ratio. Mov Disord. 2011;26(11): 1997-2003. https://doi.org/10.1002/mds.23743.

59. Benarroch EE. Locus coeruleus. Cell Tissue Res. 2017; https://doi. org/10.1007/s00441-017-2649-1.

60. Arai A, Tomiyama M, Kannari K, Kimura T, Suzuki C, Watanabe $\mathrm{M}$, et al. Reuptake of L-DOPA-derived extracellular DA in the striatum of a rodent model of Parkinson's disease via norepinephrine transporter. Synapse. 2008;62(8):632-5. https://doi.org/10. 1002/syn.20535.

61. Kempadoo KA, Mosharov EV, Choi SJ, Sulzer D, Kandel ER. Dopamine release from the locus coeruleus to the dorsal hippocampus promotes spatial learning and memory. Proc Natl Acad Sci U S A. 2016;113(51):14835-40. https://doi.org/10.1073/pnas. 1616515114.

62. Lewitt PA, Hauser RA, Lu M, Nicholas AP, Weiner W, Coppard N, et al. Randomized clinical trial of fipamezole for dyskinesia in Parkinson disease (FJORD study). Neurology. 2012;79(2):163-9. https://doi.org/10.1212/WNL.0b013e31825f0451.

63. Logan J, Wang GJ, Telang F, Fowler JS, Alexoff D, Zabroski J, et al. Imaging the norepinephrine transporter in humans with $(S, S)$ $\left[{ }^{11} \mathrm{C}\right] \mathrm{O}-$ methyl reboxetine and PET: problems and progress. Nucl Med Biol. 2007;34(6):667-79. https://doi.org/10.1016/j. nucmedbio.2007.03.013.

64. Pahapill PA, Lozano AM. The pedunculopontine nucleus and Parkinson's disease. Brain. 2000;123(Pt 9):1767-83.

65. Perry EK, Irving D, Kerwin JM, McKeith IG, Thompson P, Collerton D, et al. Cholinergic transmitter and neurotrophic activities in Lewy body dementia: similarity to Parkinson's and distinction from Alzheimer disease. Alzheimer Dis Assoc Disord. 1993;7(2):69-79.

66. Iyo M, Namba H, Fukushi K, Shinotoh H, Nagatsuka S, Suhara T, et al. Measurement of acetylcholinesterase by positron emission tomography in the brains of healthy controls and patients with Alzheimer's disease. Lancet. 1997;349(9068):1805-9. https://doi. org/10.1016/S0140-6736(96)09124-6.

67. Gilman S, Koeppe RA, Nan B, Wang CN, Wang X, Junck L, et al. Cerebral cortical and subcortical cholinergic deficits in Parkinsonian syndromes. Neurology. 2010;74(18):1416-23. https://doi.org/10.1212/WNL.0b013e3181dc1a55.

68. Bohnen NI, Muller ML, Kotagal V, Koeppe RA, Kilbourn MR, Gilman S, et al. Heterogeneity of cholinergic denervation in Parkinson's disease without dementia. J Cereb Blood Flow Metab. 2012;32(8):1609-17. https://doi.org/10.1038/jcbfm.2012.60.

69. Mesulam MM, Mash D, Hersh L, Bothwell M, Geula C. Cholinergic innervation of the human striatum, globus pallidus, subthalamic nucleus, substantia nigra, and red nucleus. J Comp Neurol. 1992;323(2):252-68. https://doi.org/10.1002/cne. 903230209

70. Zhou FM, Wilson CJ, Dani JA. Cholinergic interneuron characteristics and nicotinic properties in the striatum. J Neurobiol. 2002;53(4):590-605. https://doi.org/10.1002/neu.10150.

71. Nelson AB, Hammack N, Yang CF, Shah NM, Seal RP, Kreitzer AC. Striatal cholinergic interneurons Drive GABA release from dopamine terminals. Neuron. 2014;82(1):63-70. https://doi.org/ 10.1016/j.neuron.2014.01.023.

72. Ding Y, Won L, Britt JP, Lim SA, McGehee DS, Kang UJ. Enhanced striatal cholinergic neuronal activity mediates LDOPA-induced dyskinesia in parkinsonian mice. Proc Natl Acad Sci U S A. 2011;108(2):840-5. https://doi.org/10.1073/pnas. 1006511108. 
73. Bordia T, Campos C, McIntosh JM, Quik M. Nicotinic receptormediated reduction in L-DOPA-induced dyskinesias may occur via desensitization. J Pharmacol Exp Ther. 2010;333(3):929-38. https://doi.org/10.1124/jpet.109.162396.

74. Huang LZ, Grady SR, Quik M. Nicotine reduces L-DOPA-induced dyskinesias by acting at $\beta 2 *$ nicotinic receptors. J Pharmacol Exp Ther. 2011;338(3):932-41. https://doi.org/10.1124/jpet.111. 182949 .

75. Won L, Ding Y, Singh P, Kang UJ. Striatal cholinergic cell ablation attenuates L-DOPA induced dyskinesia in Parkinsonian mice. J Neurosci. 2014;34(8):3090-4. https://doi.org/10.1523/ JNEUROSCI.2888-13.2014.

76. Rinne JO, Myllykyla T, Lonnberg P, Marjamaki P. A postmortem study of brain nicotinic receptors in Parkinson's and Alzheimer's disease. Brain Res. 1991;547(1):167-70.

77. Shiozaki K, Iseki E, Uchiyama H, Watanabe Y, Haga T, Kameyama $\mathrm{K}$, et al. Alterations of muscarinic acetylcholine receptor subtypes in diffuse Lewy body disease: relation to Alzheimer's disease. J Neurol Neurosurg Psychiatry. 1999;67(2):209-13.

78. Kas A, Bottlaender M, Gallezot JD, Vidailhet M, Villafane G, Gregoire MC, et al. Decrease of nicotinic receptors in the nigrostriatal system in Parkinson's disease. J Cereb Blood Flow Metab. 2009;29(9):1601-8. https://doi.org/10.1038/jcbfm.2009.74.

79. Kuppenbender KD, Standaert DG, Feuerstein TJ, Penney JB Jr, Young AB, Landwehrmeyer GB. Expression of NMDA receptor subunit mRNAs in neurochemically identified projection and interneurons in the human striatum. J Comp Neurol. 2000;419(4):407-21.

80. Nash JE, Brotchie JM. Characterisation of striatal NMDA receptors involved in the generation of parkinsonian symptoms: intrastriatal microinjection studies in the 6-OHDA-lesioned rat. Mov Disord. 2002;17(3):455-66. https://doi.org/10.1002/mds.10107.

81. Ahmed I, Bose SK, Pavese N, Ramlackhansingh A, Turkheimer F, Hotton G, et al. Glutamate NMDA receptor dysregulation in Parkinson's disease with dyskinesias. Brain. 2011;134(Pt 4):97986. https://doi.org/10.1093/brain/awr028.

82. Kong M, Ba M, Ren C, Yu L, Dong S, Yu G, et al. An updated meta-analysis of amantadine for treating dyskinesia in Parkinson's disease. Oncotarget. 2017. https://doi.org/10. 18632/oncotarget.17622.

83. Fredholm BB, Svenningsson P. Adenosine-dopamine interactions: development of a concept and some comments on therapeutic possibilities. Neurology. 2003;61(11 Suppl 6):S5-9.

84. Mishina M, Ishiwata K, Kimura Y, Naganawa M, Oda K, Kobayashi S, et al. Evaluation of distribution of adenosine $\mathrm{A}_{2 \mathrm{~A}}$ receptors in normal human brain measured with $\left[{ }^{11}\right.$ C]TMSX PET. Synapse. 2007;61(9):778-84. https://doi. org/10.1002/syn.20423.

85. Ramlackhansingh AF, Bose SK, Ahmed I, Turkheimer FE, Pavese N, Brooks DJ. Adenosine 2A receptor availability in dyskinetic and nondyskinetic patients with Parkinson disease. Neurology.
2011;76(21):1811-6. https://doi.org/10.1212/WNL. 0b013e31821ccce4.

86. Mizuno Y, Hasegawa K, Kondo T, Kuno S, Yamamoto M, Japanese Istradefylline Study Group. Clinical efficacy of istradefylline (KW6002) in Parkinson's disease: a randomized, controlled study. Mov Disord. 2010;25(10):1437-43. https://doi.org/10.1002/mds.23107.

87. Potts LF, Park ES, Woo JM, Dyavar Shetty BL, Singh A, Braithwaite SP, et al. Dual K-agonist $/ \mu$-antagonist opioid receptor modulation reduces levodopa-induced dyskinesia and corrects dysregulated striatal changes in the nonhuman primate model of Parkinson disease. Ann Neurol. 2015;77(6):930-41. https://doi. org/10.1002/ana.24375.

88. Piccini P, Weeks RA, Brooks DJ. Alterations in opioid receptor binding in Parkinson's disease patients with levodopa-induced dyskinesias. Ann Neurol. 1997;42(5):720-6. https://doi.org/10.1002/ ana.410420508.

89. Glass M, Dragunow M, Faull RL. Cannabinoid receptors in the human brain: a detailed anatomical and quantitative autoradiographic study in the fetal, neonatal and adult human brain. Neuroscience. 1997;77(2):299-318.

90. Martin AB, Fernandez-Espejo E, Ferrer B, Gorriti MA, Bilbao A, Navarro $M$, et al. Expression and function of $\mathrm{CB}_{1}$ receptor in the rat striatum: localization and effects on $\mathrm{D}_{1}$ and $\mathrm{D}_{2}$ dopamine receptormediated motor behaviors. Neuropsychopharmacology. 2008;33(7):1667-79. https://doi.org/10.1038/sj.npp.1301558.

91. Sieradzan KA, Fox SH, Hill M, Dick JP, Crossman AR, Brotchie JM. Cannabinoids reduce levodopa-induced dyskinesia in Parkinson's disease: a pilot study. Neurology. 2001;57(11):2108-11.

92. Van Laere K, Casteels C, Lunskens S, Goffin K, Grachev ID, Bormans $\mathrm{G}$, et al. Regional changes in type 1 cannabinoid receptor availability in Parkinson's disease in vivo. Neurobiol Aging. 2012;33(3):620 e1-8. https://doi.org/10.1016/j.neurobiolaging. 2011.02.009.

93. Terry GE, Liow JS, Zoghbi SS, Hirvonen J, Farris AG, Lerner A, et al. Quantitation of cannabinoid CB1 receptors in healthy human brain using positron emission tomography and an inverse agonist radioligand. Neuroimage. 2009;48(2):362-70. https://doi.org/10. 1016/j.neuroimage. 2009.06.059.

94. Nishi A, Kuroiwa M, Miller DB, O'Callaghan JP, Bateup HS, Shuto $\mathrm{T}$, et al. Distinct roles of PDE4 and PDE10A in the regulation of cAMP/PKA signaling in the striatum. J Neurosci. 2008;28(42): 10460-71. https://doi.org/10.1523/JNEUROSCI.2518-08.2008.

95. Girault JA. Integrating neurotransmission in striatal medium spiny neurons. Adv Exp Med Biol. 2012;970:407-29. https://doi.org/10. 1007/978-3-7091-0932-8 18.

96. Sancesario G, Morrone LA, D'Angelo V, Castelli V, Ferrazzoli D, Sica F, et al. Levodopa-induced dyskinesias are associated with transient down-regulation of cAMP and cGMP in the caudateputamen of hemiparkinsonian rats: reduced synthesis or increased catabolism? Neurochem Int. 2014;79:44-56. https://doi.org/10. 1016/j.neuint.2014.10.004. 